\title{
ENG- AN IMPORTANT TOOL IN DIAGNOSING AND EVALUATING VERTIGO RELATED CONDITIONS
}

\author{
Kayedjohar K. Rathwala ${ }^{1}$
}

${ }_{1}^{1}$ Assistant Professor, Department of Otorhinolaryngology, Parul Institute of Medical Sciences and Research, Waghodia, Gujarat.

\section{BACKGROUND}

The symptom of vertigo or dizziness is a common complaint, for which patient seeks neuro-otological consultation. The incidence is reported to be $20 \%-30 \%$, increasing with the age. ENG is used to determine the origin of various disorders that affect the hearing and vision problems. It is a diagnostic test to record involuntary movements of the eye caused by a condition known as nystagmus. It can also be used to diagnose the cause of vertigo, dizziness or balance dysfunction by testing the vestibular system. Aims and Objectives- To decide the role of ENG in diagnosis of patients complaining of dizziness. To determine the localising value of spontaneous nystagmus, gaze nystagmus and positional nystagmus, i.e. whether they help in differentiating central from peripheral and right from left sided lesion. To determine the reliability and sensitivity of culmination frequency and maximum slow phase velocity as a parameter in qualitative analysis of nystagmus.

\section{MATERIALS AND METHODS}

This included 30 patients coming to OPD with primary complaints of balance disorders (vertigo or dizziness) between the age group of 15 - 60 years. Patients underwent thorough clinical examination. PTA and ENG were done under optimal conditions. Results were obtained in the form of butterfly chart after analysis of ENG data.

\section{RESULTS}

Of the 30 patients, 23 patients were found to have peripheral vestibular lesion and 7 patients were found to have central lesion. True vertigo was diagnosed in 7 patients among patients of study group. 17 patients presented with vertigo along with mild-tosevere SNHL. 4 patients were concluded to have Meniere's disease. Labyrinthitis due to trauma was found in 1 patient, while druginduced ototoxicity was found in 5 patients. 7 patients were diagnosed to have central pathology and 2 patients had vertebrobasilar insufficiency. Peripheral vestibular lesions are more common, partly due to their severity of presentation and also to the ease of diagnosis on clinical testing. Caloric tests are an integral part of peripheral vestibular testing. Electronys tagmography has been a vital tool in the evaluation of vestibular pathology. Culmination frequency and maximum slow phase velocity are useful parameters in qualitative analysis of nystagmus. The new test available is videonystagmography, where the patient is given a helmet to wear with all sensors and light bars embedded in it.

\section{CONCLUSION}

Nystagmus which sometimes cannot be observed and nystagmus behind closed eyes can be recorded by ENG. No significant relationship between side of lesion and directional preponderance. Presence of spontaneous nystagmus and positional nystagmus has limited localising value. Butterfly chart is a good method of graphically presenting responses of caloric test and in depicting the status of labyrinth at a glance.

\section{KEYWORDS}

Electronystagmography, Vertigo.

HOW TO CITE THIS ARTICLE: Rathwala KK. ENG- an important tool in diagnosing and evaluating vertigo related conditions. J. Evolution Med. Dent. Sci. 2018;7(17):2051-2057, DOI: 10.14260/jemds/2018/461

\section{BACKGROUND}

One of the most common presenting complaints patients bring to their family physicians is dizziness. There are types of dizziness: vertigo, light headedness, presyncope and disequilibrium. The most prevalent type is vertigo (i.e. false sense of motion), which accounts for 54 percent of reports of dizziness in primary care. ${ }^{1}$ Acute vertigo is terrifying and disabling and its duration can be a good guide to diagnosis. In BPPV it is usually less than a minute; in migraine-associated vertigo it can be from minutes to hours; in Meniere's disease

'Financial or Other Competing Interest': None.

Submission 27-03-2018, Peer Review 09-04-2018,

Acceptance 11-04-2018, Published 23-04-2018.

Corresponding Author:

Kayedjohar K. Rathwala,

D/202, Fatehsagar Complex,

Opp. Convent School, Fatehgunj,

Vadodara, Gujarat.

E-mail: drkayedjohar@yahoo.co.in

DOI: $10.14260 /$ jemds $/ 2018 / 461$ a few hours; and in acute vestibular neuritis and consolidated brainstem stroke a few days. ${ }^{2}$ The lesion may lie anywhere in the somatosensory motor chain (Peripheral nerves, spinal cord, cerebellum or cerebrum) and the clinician should enquire about symptoms represented at these various levels in the neuraxis such as weakness, numbness, incoordination, tremor, sphincters, memory and other cortical functions. ${ }^{3}$

Electronystagmography (ENG) is a test that examines the movement of eyes in order to assess how well two cranial nerves within the brain are functioning. These nerves are the acoustic (or vestibulocochlear) nerve (the nerve connecting the brain and the inner ear controlling hearing and balance) and the oculomotor nerve (the nerve connecting the brain to the muscles of the eyes).(4) ENG is used to determine the origin of various disorders that affect the hearing and vision problems. It is a diagnostic test to record involuntary movements of the eye caused by a condition known as nystagmus. It can also be used to diagnose the cause of vertigo, dizziness or balance dysfunction by testing the vestibular system. ${ }^{5}$ Our study is centered on evaluation of 
various causes of vertigo (Balance disorders) using ENG and determining its various causes. ENG is a complete diagnostic system for recording, analysing and reporting involuntary eye movements called nystagmus using electrodes feeding information into a computer.

There are four main parts to the ENG. The saccade test evaluates rapid eye movements. The tracking test evaluates movement of the eyes, as they follow a visual target. The positional test measures dizziness associated with positions of the head. The caloric test measures responses to warm and cold water circulated through a small, soft tube in the ear canal. The electrodes record the eye movements and display then on a computer screen. This allows the examiner to see how the eyes move which is very helpful in assessing balance system health. 6

\section{Aims and Objectives}

1. To decide role of ENG in diagnosis of patients complaining of dizziness.

2. To determine the localising value of spontaneous nystagmus, gaze nystagmus and positional nystagmus.

\section{Inclusion Criteria}

1. All patients attending ENT OPD of tertiary hospital with complaints of balance disorders (Vertigo, dizziness, disequilibrium).

2. All patients between the ages of 15 - 60 years.

\section{Exclusion Criteria}

1. All patients with active ear disease (Perforated tympanic membrane).

2. Patients taking medicines for vertigo.

3. Patients under the influence of alcohol, CNS medications.

4. Patients who refuse follow-up.

\section{Review of Literature}

The word "vertigo" comes from the Latin word "vertere"- to turn, the suffix "-igo"= a condition of turning about.7 Visual monitoring of eye movements being dependant on the observer, a permanent record of eye movements is obviously advantageous. As early as 1881, Hogyes inserted a light metal rod into the eyes of experimental animals. According to Aschen et $\mathrm{al}^{8}{ }^{8}$ various mechanical methods were employed to record movement of human eyes from 1891 to 1926. The classical nystagmography, using the mechanograph was described by Ohm, Majewski ${ }^{9}$ Berteles and others.

Dubois Reymond 10 in 1849 described the corneoretinal potential. Dowar, also in 1877, described the existence of a slight electric potential difference between the cornea and retina.

In 1922, Dr. Schott Koln, 11 presented the first paper on the recording of nystagmus and other eye movements by means of a voltmeter. Meyers mistakenly thought that the currents represented action potentials of the extraocular muscles.

The corneoretinal potential ${ }^{12}$ was fit clearly identified as the source of electric charge by Mower et al in 1936 and Feun and Hursh in $1937^{13}$ showed that the differences detected by the electrodes placed near the eye (due to changes in the corneoretinal potential) were proportional to the angle of the deviation of the eyes thus forming the basis for the modern technique and principle of electronystagmography. ${ }^{14}$

\section{MATERIALS AND METHODS}

\section{The ENG Procedure}

The study was conducted in the ENT department of tertiary hospital on 30 OPD patients, who presented with chief complaints of vertigo (Dizziness).

- The procedure was conducted on an OPD basis and no patients were admitted. After explaining in detail about the nature and duration of the investigation and consent required for the same was taken in writing.

- ENG tests were done by the thesis candidate after getting adequate training and knowledge and proper precautionary measures were taken.

- Reports were generated after due analysis using the prescribed software using RMS ENG version 1.0.127 and results were generated using a standard desktop computer.

- The youngest person in the study was of age of 15 years and eldest was 60 years.

- Patients with difficulty in understanding and obeying instruction, claustrophobia, tremors, difficulty in focusing of objects, cervical spondylosis and those suffering from psychiatric illness were excluded from the study after excluding the patients from the exclusion criteria mentioned above.

\section{Study Type}

Observational Cross-Sectional Study.

\section{Consent}

All eligible participants were individually given an initial description of the proposed study. Participants were then presented a written informed consent form. After explaining participant information sheet and consent form in local (Gujarati and Hindi) language, informed written consent of participants was obtained.

\section{Equipment}

The setting up of an ENG laboratory will require certain equipment. The room selected for ENG should be of adequate size (about $3 \mathrm{~m} * 4 \mathrm{~m}$ ), quiet and light-proof. An airconditioned room is preferable. It should be away from operation theatres, where casualty machines are used and from other heavy electrical equipment like $x$-ray machines etc. 15

The ENG machines to be used may be single or multichannelled as available. A multichannel machine is of course preferable, but a single channel machine is certainly adequate for routine clinical testing. The machine should be properly grounded.

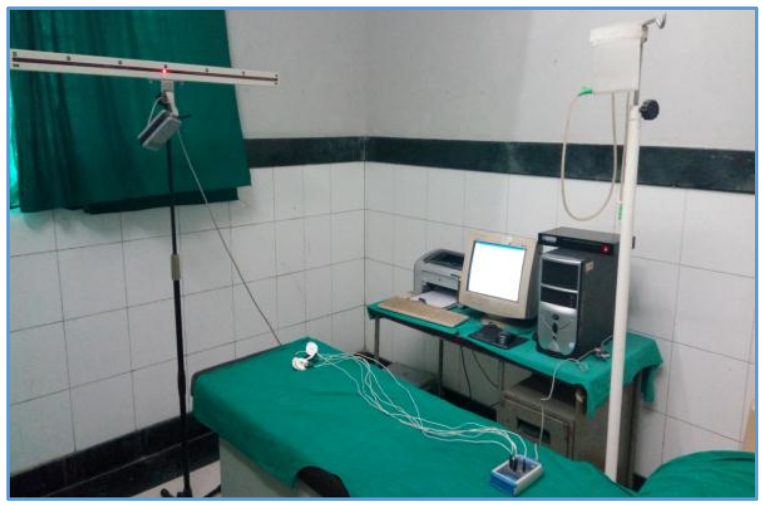


A bed or table, or a positioning chair is necessary for the patient to lie on. It should be having a mechanism by which its head end can be raised to 30 degrees above the horizontal. It is preferable to tilt the entire table, so that the patient does not have to bend at the waist or neck. This avoids any possible vestibular stimulation from somatosensory afferents from the trunk or neck regions.

A calibration cross can be easily fabricated. The arms of the cross which can be placed horizontally or vertically carry small light bulbs, which when kept at a fixed distance from the patient (1 meter from the foot end of the patient) subtend a known angle at the patient's nasion (usually 20 degrees). This cross can also be used for the gaze test. The calibration of the horizontal eye movements is done as follows: the patient is asked to transfer his gaze from one bulb to another in the horizontal or vertical plane by alternately switching the lights on and off, and these eye movements are recorded. This method however has one disadvantage, viz. when the subject rapidly shifts his gaze from one point to another, the eyes may execute some small movement before coming to rest on the point.

These micronystagmic movements make accurate calibration difficult. This problem is avoided by using a calibration pendulum, which swings to and fro with a known amplitude. The patient's eyes smoothly track a light bulb mounted on the end of this pendulum, thus avoiding the micronystagmic movements and ensuring accurate calibration. This calibration can be one for horizontal and vertical eye movements.

The pendular calibration also tests the optokinetic function of smooth pendular stimulus tracking (vide infra).

Two thermostatically controlled caloric water baths are necessary, one for warm (44 degree C) and one for the cold (30 degree C) stimulus. An irrigation apparatus attached to this water bath is not essential, as irrigation can be easily done manually with $20 \mathrm{~mL}$ glass syringes, which between irrigations are kept suspended in the corresponding water baths to maintain their uniform temperature.

Two small polythene catheters about $3 \mathrm{~mm}$ in diameter and $20 \mathrm{~cm}$ in length are needed for injecting the water into the external auditory canals. Infant feeding tubes with their tips cut off or scalp vein needle sets minus the needle and flange can be used for this purpose. The returning water is collected in a kidney tray or by attaching polythene bags to the pinna. The catheters and polythene bags are held by in place by adhesive tapes.

A stop watch is essential to ensure uniform irrigation of the water during the caloric test and also note the duration of recording for the spontaneous gaze and caloric nystagmus.

An air caloric irrigator is essential for doing the caloric test in patients with perforation or operated mastoid cavity. The machine should be capable of delivering air at 25 degree $\mathrm{C}$ to 50 degree $\mathrm{C}$ at a flow rate of up to 8 litres per minute.

\section{Preparation of the Patient}

The patient is instructed to avoid alcohol and certain drugs (Sedatives, hypnotics, antihistamines, any anti-vertigo medication, etc.) he may be taking for at least $48 \mathrm{hrs}$. before the test. The external auditory canals are examined for wax, discharge, infection, perforation of the tympanic membrane or an operated mastoid cavity. The areas where the electrodes are to be applied are cleansed with spirit or alcohol to remove grime, so as to ensure good skin-electrode contact. The cups of the electrodes are then filled with electrolyte paste and the electrodes are firmly applied to the respective sites with lead-free adhesive tape. As mentioned before, for a mono-channel record of conjugate horizontal eye movements, the electrodes are applied to the skin of the temples just lateral to the outer canthi (Fig). The neutral electrode is applied on the forehead or to the right forearm or leg. For a four-channel recording, electrodes are applied just lateral to outer canthi, at the glabella and above and below the left eye (Fig). The neutral electrode is fixed on the right forearm or leg.

We normally do a four-channel recording where the first channel records the horizontal conjugate eye movements. The second channel records the vertical movements of the left eye. The third channel records the horizontal movements of the right eye and the fourth channel records the horizontal movements of the left eye.

The polythene catheter is gently introduced into the external auditory canal and is gradually advanced along the posterior wall of the canal till its tip lies close to the tympanic membrane. If the catheter touches the tympanic membrane, the patient immediately complains of pain and the catheter should be slightly withdrawn and fixed to the skin of cheek with adhesive tape. When the patient is put in the caloric position, the tip of the catheter comes to lie close to the postero-inferior quadrant of the tympanic membrane. A catheter is similarly introduced into the opposite ear. A small polythene bag is fixed to each pinna enclosing the latter, so that the returning water collects in the bag without disturbing the patient.

The patient thus prepared is asked to lie down on the table. The electrode cables are connected to the junction box of the machine. The patient is now ready for testing.

\section{The Limitations of ENG may be Summarised as ${ }^{16}$}

1. Many patients with definite and reliable history of vertigo have normal ENG (poor sensitivity). This is because the lesion is in the anatomical sites and reflex mechanisms not tested by ENG. For example, a balance disorder due to a lesion in the vestibule- spinal system like tabes dorsalis will have normal ENG findings.

2. Differentiation between normal and abnormal and peripheral from central is not very clear- cut in some cases. Multifactorial causes of eye movement contaminate the ENG recordings.

3. Cooperation of the patient is not always available. Without adequate mental and physical cooperation, a clean recording is not obtained.

4. Monitoring progress of the disease is not possible in many cases.

\section{Risks of ENG Tests}

1. There are very few risks with ENG. Some people may have dizziness or nausea during the test.

2. ENG should not be used if you have a pacemaker, because the equipment may interfere with pacemaker function.

3. Rapid changes in position required for the test may aggravate back or neck problems.

4. The water caloric test may cause mild discomfort. If you have been previously diagnosed with a perforated 
tympanic membrane, you should not undergo the water caloric portion of the ENG test.

5. There may be other risks depending on your specific medical condition. Be sure to discuss any concerns with your healthcare provider before the procedure.

\section{Certain Factors or Conditions may interfere with ENG. These Include-}

- Earwax.

- Impaired vision.

- Frequent blinking.

- Certain medicines such as sedatives, tranquilisers and anti-vertigo medicines.

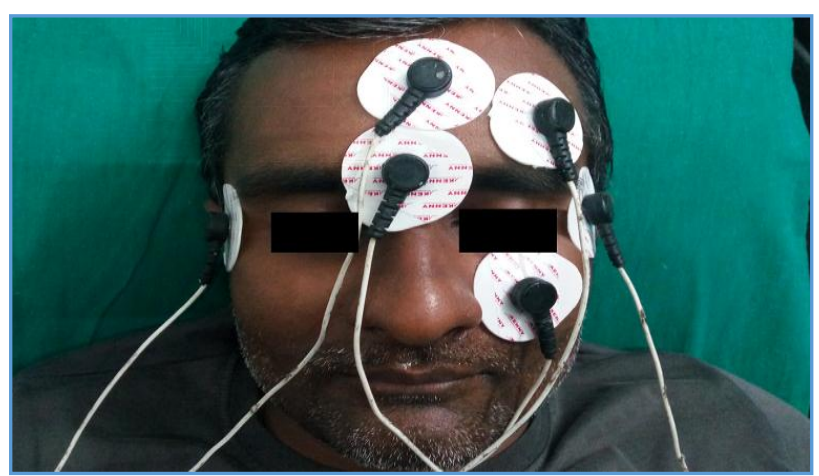

\section{Calibration}

The test begins with acquisition of chorioretinal potential by the affixed leads and their display on the active screen. The equipment is calibrated initially for 30 seconds to identify the normal voluntary movements of the patient's eyes. The battery of tests include: gaze and spontaneous nystagmus testing, saccadic testing and finally caloric testing. These tests were performed after considering presenting symptom and due clinical examination.

Warm caloric testing was done with water at $44^{\circ} \mathrm{C}$ and continued for 30 seconds. After allowing the stimulated SCC to recover for 8 mins, cold caloric test was done using water at $30^{\circ} \mathrm{C}$. All nystagmus was allowed to disappear completely before the next test was commenced. The data obtained were analysed in the form of butterfly chart.

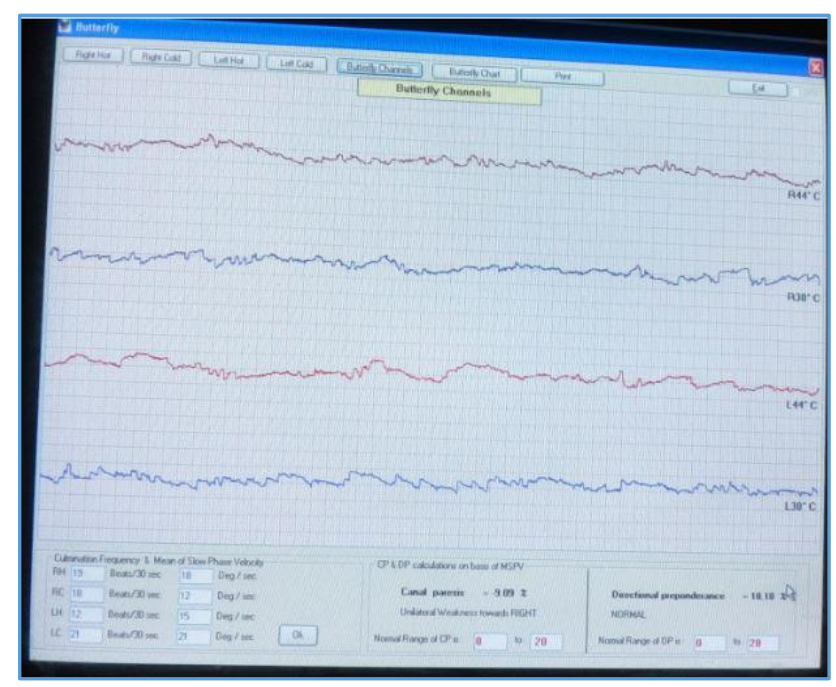

\section{Electrical Calibration}

Many of the ENG machines have a built-in calibration system, wherein an impulse of known voltage can be generated. The sensitivity of the machine is so adjusted that a 200 microvolt signal produces a $10 \mathrm{~mm}$ deflection of the recording needle (Fig). Thus, the amplitude of the patient's nystagmus can be measured in $\mathrm{mm}$ and readily converted into microvolts. It should be noted that ambient electrical disturbances can produce movements of the recording needle, but these usually have amplitude of less than 20 microvolts. Therefore, any beat less than $1 \mathrm{~mm}$ in height should not be considered as nystagmus, because it is less than 20 microvolts in amplitude. ${ }^{17}$

The amplitude of the nystagmus measured in microvolts will be directly dependent on the intensity of the existing corneoretinal potential. If the corneoretinal potential is very low due to some retinal disorder. The amplitude of the nystagmus will also be correspondingly low in spite of normal excursion of the eye balls. The frequency and slow phase velocity of the nystagmus are, however, independent of the intensity of the corneoretinal potential.

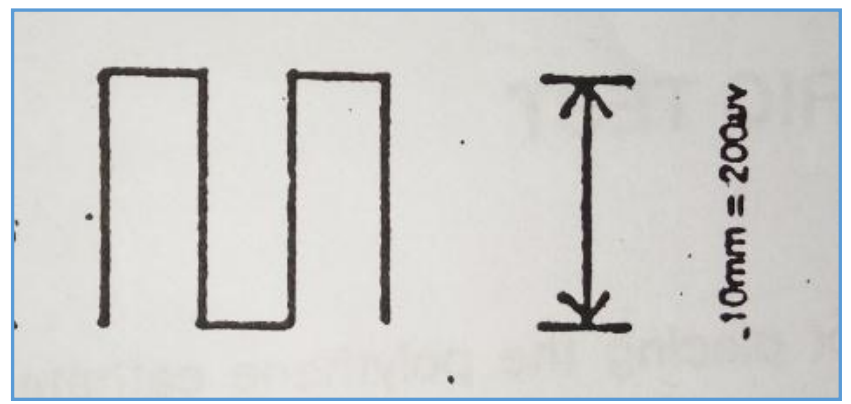

\section{Biocalibration 18}

This is done by using the pendulum (Fig). The pendulum is mounted in an inverted fashion. The fulcrum is attached to the head end of the table at the level of the patient's nasion when calibrating horizontal eye movements. The arm of the pendulum below the fulcrum carries a heavy weight to ensure stability and smooth and consistent movement of the pendulum. The arm that rises vertically above the table is 1 meter long and carries a small projecting rod with a light bulb, so that the bulb is directly above the patient's eyes. The patient is asked to look at the bulb and follow its movements, as it swings from side to side for 10 cycles. These eye movements are recorded (Fig). The amplitude of the pendulum usually used is $40^{\circ}\left( \pm 20^{\circ}\right)$. Besides calibration, it is also a test for the optokinetic function of smooth pendular stimulus tracking. For calibrating the vertical eye movements, the pendulum should be mounted on the side of the table.

\section{The Butterfly Chart}

The data obtained from the evaluation of spontaneous and caloric nystagmus reactions are represented on a synoptical chart. The chart consists of 4 quadrants each, representing one caloric reaction. In each quadrant, the abscissa or the horizontal axis represents time $(30$ seconds of the culmination phase) and the ordinate or the vertical axis represents the number of nystagmus beats (Culmination frequency). Let us consider the quadrant for the right ear 44 $\mathrm{C}$ caloric reactions. The horizontal axis represents time (1 $\mathrm{mm}=1 \mathrm{sec}$ ). In the chart, it is $30 \mathrm{~mm}$ long and represents 30 
seconds. The vertical axis represents number of beats $(1 \mathrm{~mm}$ $=1$ beat). The number of nystagmus beats per 30 seconds in the culmination phase of the caloric response is plotted on the vertical axis. The normal range of caloric response is superimposed on the vertical axis of the quadrant. Responses within this range are considered normal, those below it as hypoactive and those above it as hyperactive. The butterfly chart consists of 4 such quadrants for the four caloric reactions, each with its corresponding normal range. For convenience, the responses are designated by digits as follows. ${ }^{19}$

Normal $=0$.

Hypoactive $=1$.

Hyperactive $=2$.

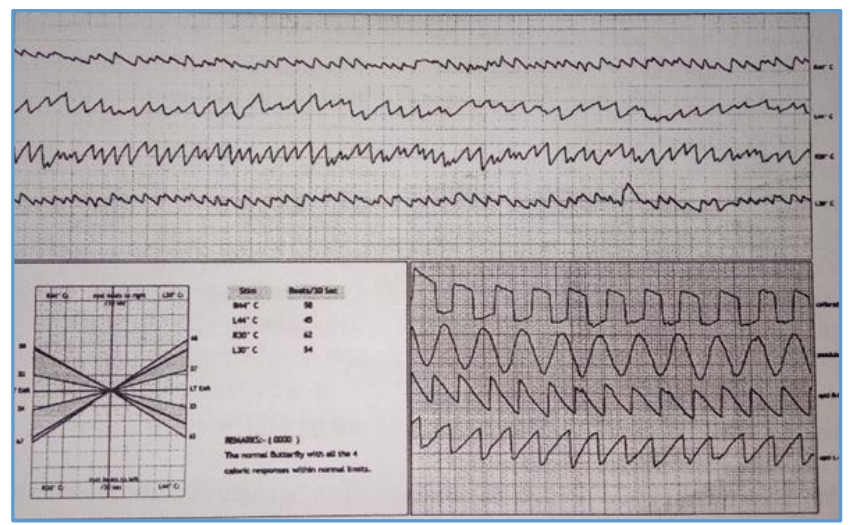

The computer automatically plots the Butterfly Chart from the Culmination Frequency and also calculates the speed of slow phase. The non-caloric portions of the ENG tests, viz. the calibration test, the test for gaze nystagmus, the test for spontaneous nystagmus as well as positional tests are also documented by the computerised ENG machine. ${ }^{20}$

\section{RESULTS}

Case Analysis

\begin{tabular}{|c|c|}
\hline Sex & No. of Cases \\
\hline Females & 17 \\
\hline Males & 13 \\
\hline Total & $\mathbf{3 0}$ \\
\hline Age in Years & No. of Cases \\
\hline $15-30$ & 07 \\
\hline $31-45$ & 14 \\
\hline $46-60$ & 09 \\
\hline Total & $\mathbf{3 0}$ \\
\hline \multicolumn{2}{|c|}{ Age and Sex Distribution } \\
\hline
\end{tabular}

\begin{tabular}{|c|c|}
\hline Type of Vertigo & No. of Cases \\
\hline Rotatory & 25 \\
\hline Non-Rotatory & 05 \\
\hline Total & $\mathbf{3 0}$ \\
\hline \multicolumn{2}{|c|}{ Presenting Symptoms } \\
\hline
\end{tabular}

\begin{tabular}{|c|c|}
\hline Characteristics of Dizziness & No. of Cases \\
\hline Swaying & 12 \\
\hline Instability & 08 \\
\hline Blackouts & 03 \\
\hline True vertigo & 07 \\
\hline Total & 30 \\
\hline
\end{tabular}

\begin{tabular}{|c|c|}
\hline Types of Dizziness & No. of Cases \\
\hline Episodic vertigo & 20 \\
\hline Positional vertigo & 04 \\
\hline Continuation vertigo & 06 \\
\hline Total & $\mathbf{3 0}$ \\
\hline
\end{tabular}

\begin{tabular}{|c|c|}
\hline Duration of Dizziness & No. of Cases \\
\hline $0-6$ months & 15 \\
\hline$>6$ months -1 year & 05 \\
\hline$>1$ year -2 years & 02 \\
\hline$>2$ years -5 years & 05 \\
\hline$>5$ years & 03 \\
\hline Total & $\mathbf{3 0}$ \\
\hline
\end{tabular}

\begin{tabular}{|c|c|}
\hline Associated Symptoms & No. of Cases \\
\hline Nausea and Vomiting & 15 \\
\hline Tinnitus & 03 \\
$\bullet \quad$ Unilateral & 09 \\
\hline Deafness & 05 \\
$\bullet \quad$ Unilateral & 12 \\
\hline Bilateral & 27 \\
\hline Headache & 06 \\
\hline Blackouts & 01 \\
\hline Speech difficulties & \\
\hline
\end{tabular}

\begin{tabular}{|c|c|}
\hline H/O Drugs or Medical Diseases & 13 \\
\hline H/O Noise exposure & 02 \\
\hline H/O Head injury & 04 \\
\hline
\end{tabular}

\section{Local Examination-}

\section{Ears}

Tympanic membrane was found to be normal in all 50 cases.

\begin{tabular}{|c|c|}
\hline Hearing Test & No. of Cases \\
\hline Normal & 13 \\
\hline S.N. Hearing Loss & \\
$\bullet \quad$ Unilateral & 05 \\
$\bullet \quad$ Bilateral & 12 \\
\hline Total & $\mathbf{3 0}$ \\
\hline
\end{tabular}

\begin{tabular}{|c|c|}
\hline Spontaneous Nystagmus & No. of Cases \\
\hline Right beating & 03 \\
Left beating & 08 \\
\hline
\end{tabular}

\section{CNS Examination}

CNS examination was found normal in most of the patients.

\begin{tabular}{|c|c|}
\hline Sensorineural deafness & 17 \\
\hline Right ear & 02 \\
\hline Left ear & 03 \\
\hline Bilateral & 12 \\
\hline \multicolumn{2}{|c|}{ Pure Tone Audiometry } \\
\hline
\end{tabular}

\section{ENG}

\begin{tabular}{|c|c|}
\hline ENG closed & 08 \\
Eyes open & 12 \\
\hline \multicolumn{2}{|c|}{ Spontaneous Nystagmus } \\
\hline \multicolumn{2}{|c|}{} \\
\hline Right beating & 10 \\
Left beating & 08 \\
Direction changing & 02 \\
Total Gaze Nystagmus \\
\hline \multicolumn{2}{|c|}{} \\
\hline
\end{tabular}




\section{Final Diagnosis}

ENG findings were correlated with history, clinical examination and investigations and following diagnoses were established.

\begin{tabular}{|c|c|c|c|}
\hline Sr. No. & Disease & Actual No. & (\%) \\
\hline 1 & Meniere's disease & 04 & 13 \\
\hline 2 & Post-traumatic vertigo & 01 & 03 \\
\hline 3 & $\begin{array}{c}\text { Acute vestibular } \\
\text { neuronitis }\end{array}$ & 05 & 17 \\
\hline 4 & Noise-induced trauma & 02 & 07 \\
\hline 5 & $\begin{array}{c}\text { Ototoxicity } \\
\text { (Streptomycin) }\end{array}$ & 05 & 17 \\
\hline 6 & Central Pathology & 07 & 22 \\
\hline 7 & $\begin{array}{c}\text { Vertebrobasilar } \\
\text { insufficiency secondary } \\
\text { to hypertension and } \\
\text { diabetes mellitus, } \\
\text { spondylosis }\end{array}$ & 02 & 07 \\
\hline 8 & Uncertain (BPPV) & 02 & 07 \\
\hline 9 & $\begin{array}{c}\text { No specific diagnosis } \\
\text { (normal ENG) }\end{array}$ & 02 & 07 \\
\hline & Total & $\mathbf{5 0}$ & $\mathbf{1 0 0}$ \\
\hline
\end{tabular}

\section{Standardisation}

The dispersion of normal canal paresis (CP) and directional preponderance (DP) measures have been investigated and various values have been suggested.

\begin{tabular}{|c|c|c|c|}
\hline Reference & C.P. & D.P. & Eyes \\
\hline Aschen et al & $16 \%$ & $18 \%$ & Closed \\
\hline Brookier and Pulec & $24 \%$ & $28 \%$ & Closed \\
\hline Coats & $18 \%$ & $26 \%$ & Closed \\
\hline Hamid et al & $47 \%$ & $28 \%$ & Open and Covered \\
\hline Henrikson & $18 \%$ & $16 \%$ & Open and Covered \\
\hline Jonkees et al & $16 \%$ & $18 \%$ & Closed \\
\hline Preber & $10 \%$ & $12 \%$ & Closed \\
\hline
\end{tabular}

These values are relative, i.e. responses obtained from irrigating two ears are compared with each other. In this study, these values were established as accepted forms.

\section{DISCUSSION}

The purpose of the ENG is to determine whether or not dizziness may be due to inner ear disease. There are four main parts to the ENG. The calibration test evaluates rapid eye movements. The tracking test evaluates movement of the eyes, as they follow a visual target. The positional test measures dizziness associated with positions of the head. The caloric test measures responses to warm and cold water circulated through a small, soft tube in the ear canal.

ENG is useful for diagnosis of vestibular neuritis, BPPV and bilateral vestibular loss. The calibration and tracking tests are intended to diagnose central nervous system disorders like cerebellar degeneration. ${ }^{21}$

Our study group of 30 patients was subjected to ENG under the same conditions and using the same equipment to obtain a homogenous result. Majority of the patients were quite cooperative. Patients who have not been able to go through certain tests as per pre-decided proforma have been excluded from the study. Interpretation of ENG results are based on the response of the vestibular system to stimuli from change in position and to caloric stimulation. The result is obtained in the form of butterfly chart, which is a graph depicting the nystagmus response to caloric stimulation. The response may be normal, hyperactive or hypoactive. ${ }^{22}$

In our study, 30 patients were examined and studied. It comprised of 13 males and 17 females. The symptom complex of vertigo as mentioned above was taken into account. The complaints of true vertigo were more common in females of the study group. True vertigo was diagnosed in 7 patients among patients of study group. 17 patients presented with vertigo along with mild-to-severe SNHL. 4 patients were concluded to have Meniere's disease. Druginduced ototoxicity was found in 5 patients. 7 patients were diagnosed to have central pathology and 2 patients had vertebrobasilar insufficiency. $23 \%$ of the patients in our study fell into the age group of $<30$ years of age. The duration of a vertigo episode and the recovery time was found to be less for this category of people than the other age groups.

Dix-Hallpike manoeuvre was performed in all patients and $20 \%$ patients had discomfort during the test. Among this 2 patients were primarily diagnosed to have BPPV following their evaluation with thorough clinical examination and supported by ENG to rule out other causes. BPPV is the most prevalent peripheral vestibular lesion. ${ }^{23}$ Dix-Hallpike manoeuvre to diagnose posterior canal BPPV was first described in 1952. The typical nystagmus will show a latency of 1 - 5 before onset and will usually resolve in less than a minute. This vertigo is not usually associated with nausea or vomiting. In patients with a definitive diagnosis, for e.g. BPPV, Epley's particle repositioning manoeuvre was done as treatment measure.

In our study 23 cases were diagnosed to have peripheral vestibular lesions, while 7 cases showed central pathology. This is in favour of other studies using ENG with $65 \%$ of cases falling under peripheral pathology. The incidence of vestibular diseases were further evaluated in studies conducted by Tomanovic et al and Baloh et al using computerised ENG, which yielded a predominance of central vestibular lesions.

The causes of a central vestibular lesion can be attributed to a wide range of intracranial and extracranial pathologies. Vertebrobasilar artery insufficiency is a major cause of ischaemia to the central vestibular areas producing vertigo. In our study, 2 patients were confirmed to have been suffering from vertebrobasilar insufficiency related vertigo. This could be confirmed by Doppler studies conducted on the blood flow in these vessels. These findings are further corroborated in the work of Arne Kentala et al, in which he diagnosed 132 cases of central vestibular lesions with the help of ENG test. Radiological and other investigations were used in the diagnosis of central pathology. In patients with diagnosis suggestive of central pathology, further investigations like MRI or CT were advised to ascertain the diagnosis and required treatment.

Peripheral vestibular lesions are more common partly due to their severity of presentation and also to the ease of diagnosis on clinical testing. However, the side of the lesion is not easily identified and presence of bilateral peripheral disorders further complicates matters.

Benign paroxysmal positional vertigo presents with a history of brief, episodic position provoked vertigo. On provocation with Dix-Hallpike manoeuvre, BPPV displays an intense burst of nystagmus activity. ${ }^{24}$

The other peripheral disorder diagnosed was Meniere's disease, which affected 4 patients. The vestibular testing may 
show varying responses, progressive dysfunction from a hyperactive to a normal and then a decreased response in advanced stages of disease.

Post-traumatic vertigo is the next major group in peripheral pathology. This is mostly due to the displacement of otoconia into the SCC, most commonly the posterior SCC. In our patients, we diagnosed 1 patient with peripheral vestibular lesions following head trauma. Attempts were made to reposition the displaced otoconia by Epley's manoeuvre.

Post-viral labyrinthitis or Vestibular neuronitis is a transient disorder occurring spontaneously and will resolve with supportive care. In our group, we found such 5 patients suffering from neuronitis.

Caloric tests are an integral part of peripheral vestibular testing. We subjected all patients to bithermal caloric testing with the patient placed in supine position with head-end elevation of $30^{\circ}$ to place the horizontal SCC in the vertical plane to ensure maximal stimulation.

Denis Bojrab et al conducted caloric testing at varying angles of elevation to finally determine $25^{\circ}-30^{\circ}$ for optimal stimulation of the horizontal SCC. This test is poorly tolerated with patients complaining of discomfort during the procedure. The risk of otomycosis in leaving the ear moist after the procedure was kept in mind and the ears were dried with cotton wicks. Stockwell reported a high incidence of post caloric complications in his follow-up study of 40 patients. ${ }^{11}$

Electronystagmography has been vital tool in the evaluation of vestibular pathology. ENG testing has a number of advantages. The results are well quantified, and the normal limits are well defined. It imparts more precision and response quantification to caloric testing. It can be used for the follow-up of patients with chronic vestibular disorders.

\section{CONCLUSION}

1. Nystagmus which sometimes cannot be observed and nystagmus behind closed eyes can be recorded by ENG.

2. No significant relationship between side of lesion and directional preponderance.

3. Presence of spontaneous nystagmus and positional nystagmus has limited localising value.

\section{REFERENCES}

[1] Hanley K, O'Dowd T, Considine N. A systemic review of vertigo in primary Care. $\mathrm{Br} \mathrm{J}$ Gen Pract 2001;51(469):666-71.

[2] Gresty MA, Bronstein AM, Brandt T, et al. Neurology of otolith function. Peripheral and central disorders. Brain 1992;115(Pt 3):647-73.

[3] Bronstein AM. Evaluation of balance. Scott-Brown's otorhinolaryngology, head and neck surgery. Vol 3. 2008;240b:3706.

[4] Electronystagmography (ENG) (n.d) Johns Hopkins Medicine.

http://www.hopkinsmedicine.org/healthlibrary/test_ procedures/neurological/electronystagmography_eng _92, P07659/

[5] Griggs RC, Jozefowicz RF, Aminoff MJ. Approach to the patient with neurologic disease. Chap - 418. In: Goldman L, Ausiello D, eds. Cecil medicine. 23rd edn. Philadelphia, PA: Elsevier Saunders 2007.
[6] Sanders DB, Howard JF. Neuro-otology: laboratory investigations in diagnosis and management of neurootological disorders. Chap - 40. In: Bradley WG, Daroff RB, Fenichel GM, et al. eds. Bradley: neurology in clinical practice. $5^{\text {th }}$ edn. Philadelphia, PA: Butterworth-Heinemann Elsevier 2008.

[7] Meyerhoff WL, Cooper JC. Tinnitus. In: Paparella MM, edr. Otolaryngology. $3^{\text {rd }}$ edn. Philadelphia: Saunders 1991:1169-75.

[8] Watson P, Barber HO, Deck J, et al. Positional vertigo and nystagmus of central origin. Can J Neurol Sci 1981;8(2):133-7.

[9] Majewski S. Gnatofizjologia stomatologiczna. (Dental gnathophysiology. Occlusal norms and stomatognatic system functions). Warszawa/Lviv, PZWL, 2007/2008.

[10] Du Bois-Reymond EH. Untersuchungen Ueber Thierische Elektricität. Vol. 1. Berlin: G Reimer Publisher 1848: p. 56+743.

[11] Stockwell CW. Nystagmography. In: Webster JG, edr. Encyclopedia of medical devices and instrumentation. Vol 3. New York: John Wiley \& Sons 1922: p. 2090-4.

[12] Arden GB, Barrada A, Kelsey JH. New clinical test of retinal function based upon the standing potentials of the eye. Brit J Ophthalmol 1962;46(8):449-67.

[13] Barry W, Jones GM. Influence of eye lid movement upon electro-oculographic recording of vertical eye movements. Aerosp Med 1965;36:855-8.

[14] Claussen CF, De Sa JV. Clinical study of human equilibrium by electronystagmography and allied tests. Bombay: Popular Prakashan 1978.

[15] Hood JD. Electronystagmography. J Laryng 1968;82:167-83.

[16] Daspit CP, Churchill D, Linthicum FH. Diagnosis of perilymph fistula using ENG and impedance. Laryngoscope 1980;90(2):217-23.

[17] Krynycky IA, Mutticci KF. Electronystagmography in the examination of dizzy patient. Ear Nose Throat J 1979;58(10):31-9.

[18] Kirtane MV. Standardization in electrostasmography. Ind J Otolaryng 1979;31(4):126-32.

[19] Kirtane MV. A systemic approach to electrostasmography. Bombay, India: Popular Prakashan 1982.

[20] Kacker SK. Correlation of MVSP and frequency of nystagmus in diagnosis. Indian Journal of Otolaryngology 1981;33(2):49-51.

[21] Stockwell CW. Incidence of electrostasmography abnormalities. Insights in Practice. ICS Medical Corporation, May 2000.

[22] Coats AC. Computer-quantified positional nystagmus in normal. Am J Otolatyngol 1993;14:314-26.

[23] Baloh RW, Konrad HR, Dirks D, et al. Cerebellarpontine angle tumors. Results of quantitative vestibulo-ocular testing. Arch Neurol 1976;33(7):50712.

[24] Brandt T. Benign paroxysmal positioning vertigo. In: Brandt T, edr. Vertigo: its multisensory symptoms. $2^{\text {nd }}$ edn. London: Springer-Verlag 1999: p. 251-7. 